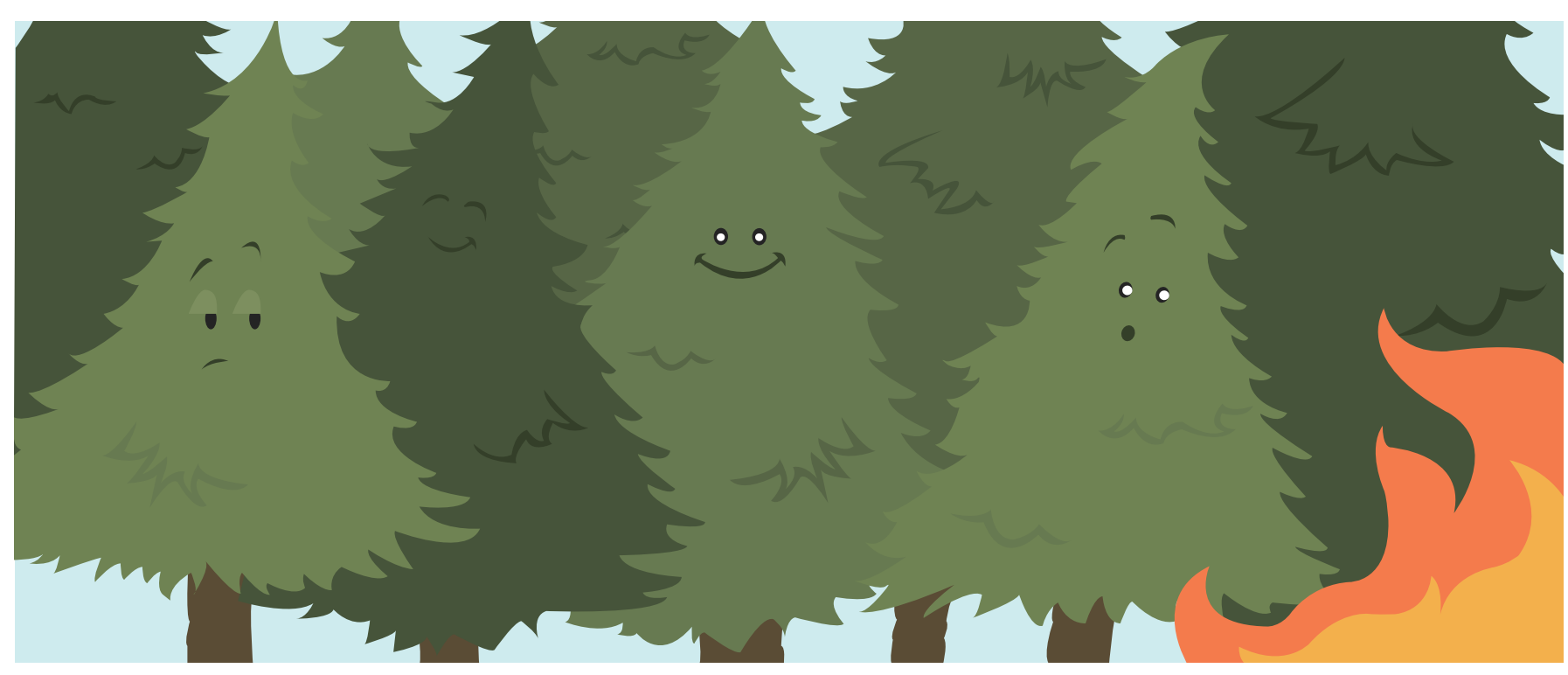

\title{
HOW DO TREES RESPOND TO STRESS?
}

\section{Karina V. R. Schäfer ${ }^{1 *}$ and Dirk W. Vanderklein ${ }^{2}$}

${ }^{1}$ Department of Biological Sciences, Rutgers University, Newark, NJ, United States, ${ }^{2}$ Department of Biology, Montclair State University, Montclair, NJ, United States

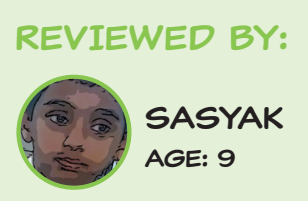

Trees are a lot like people: they experience stress and they get infected with bugs or diseases and they can be attacked by fire, windstorms, floods, and droughts. We call these things that attack or infect trees disturbances. Trees are not like people, because they cannot go to the doctor to get better and they cannot move away from whatever is disturbing them. This last part is very important because it means that, in order for trees to have existed for hundreds of millions of years, they must have had the ability to cope with disturbances without a doctor. As you may imagine, different kinds of trees have evolved different ways to deal with certain disturbances. This is what we have learned from our research in an area called the Pine Barrens of New Jersey on the East Coast of the United States.

\section{WHY IS IT IMPORTANT TO UNDERSTAND HOW TREES RESPOND TO STRESS?}

Trees are important for humans and other animals for a variety of reasons. Humans depend on trees for wood, paper, air cooling, and water cleaning; and animals depend on trees for food and shelter. We call these things services. 
PHOTOSYNTHESIS

The process by which plants take up carbon dioxide and release water and oxygen.

\section{FOREST}

\section{DISTURBANCE}

A stress experienced by a forest. Forest disturbances include certain insect pests, hurricanes, floods, and droughts.

\section{ADAPTATION}

A process by which plants or animals become better able to live in a given environment over each generation. Adaptation can take place over a relatively short period of time, such as a few years, or over a very, very long time, such as thousands of years or longer. In the Pine Barrens, thick bark is considered an adaptation to fire, because trees with thick bark survive a fire better than trees with thin bark.
Therefore, how trees respond to different disturbances or stresses is extremely important, because the services trees provide need to be maintained or enhanced if we want to keep on using those services. One of the reasons we want to know how trees respond to different disturbances or stresses is so that we can understand, and maybe predict, how trees will respond to changes in these disturbances and stresses in the future.

Trees, like all plants, soak up carbon dioxide from the air with the help of light and, in the process, release water and oxygen. This process is called photosynthesis and it is an important service that trees provide. In our research, we investigate how much water and carbon are being processed by these trees and how that may change in the future because of climate change. The amount of wood that trees make is related to how much carbon dioxide they soak up from the air, because the more they soak up, the more the trees grow and therefore the more wood they produce. Likewise, the more carbon dioxide the trees soak up, the more water they release. This means that trees have to have a way to control how much water they lose as they take in carbon dioxide, or they will dry out. We have a similar problem. When we breathe out we also lose water, which you can see when you breathe against a cold glass and condensation forms on the glass. The condensation is the water that you are losing. If we lose too much water, we will also dry out! When trees experience a disturbance (like an insect chewing its leaves), their capacity to soak up carbon dioxide and therefore to grow is strongly reduced. Similarly, the ability of the trees to supply us with wood is decreased. All of this means that our wood and water supplies are dependent on the way trees respond to disturbances. On top of this, climate change may lead to an increased number of forest disturbances, which trees might not be able to handle. And as you now know, this would mean that we would suffer as well.

\section{WHERE WE STUDIED THE TREES}

We conducted the study in the New Jersey (NJ) Pine Barrens, which is a globally unique ecosystem that covers roughly a third of the state of New Jersey (on the east coast of the United States). This area has all kinds of interesting plants and animals and even a mythical creature called the Jersey Devil. The NJ Pine Barrens is concentrated in the southern half of the state where it is relatively flat and the soil is mostly sand, so it is quite dry most of the time. The number one disturbance that occurs in the NJ Pine Barrens is fire. The forest of pine and oak trees exists there because they have adaptations that allow them to survive and grow where fires occur while many other tree species do not have those adaptations and therefore cannot grow there as long as there are fires. What this means, though, is that if fire is prevented from happening the oaks and pines have to compete with the tree species that grow better when there is no fire and this eventually leads to a change 
in which species of trees exist in the forest. This also means that this forest was established over thousands of years as a result of relatively frequent fires. As people moved into the area, the frequency of naturally occurring fires decreased drastically, but fires caused by humans still occur, mostly as a way to keep the tree species in the Pine Barrens, in a way to keep it the Pine Barrens, which are called prescribed fires. All of the tree species that grow in the Pine Barrens have similar features, called adaptations, to help them survive fire, but the way each species of trees reacts after the fire appears to be different. Adaptations in trees to survive fires include having a thick bark to protect them and the ability to regrow after a fire. Another major environmental disturbance that the trees in the Pine Barrens have to deal with is low water availability. The trees in this area have adaptations for that, too. Oaks, for example, can have very long roots reaching deep down into the earth where there is water, and this allows them to survive through long periods of drought (dry weather). A third disturbance that trees in the Pine Barrens face is attack by Gypsy moth caterpillars. Gypsy moths are insects, and their caterpillars chew on the leaves of oaks. The trees in the Pine Barrens have not had to deal with Gypsy moths for very long, so they do not have any adaptations yet to protect them from attack by these insects.

Lots of studies have looked at how individual trees respond to different disturbances over a few years, but very few studies have looked at how trees respond over a longer period of time. It is also important to know whether all tree species respond in the same way to a given disturbance, or whether different tree species have different kinds of adaptations. Last, we know that trees often experience more than one disturbance at the same time, so it is also important to understand how a combination of disturbances affects trees in the long run. We set out to address these questions by looking at different tree species in a part of the Pine Barrens how they responded to fire, insect attack, and drought over a long time, a 10-year period.

In order to study the impacts of fire on tree growth and function, we set up

PRESCRIBED

\section{BURNING}

A forestry technique where the undergrowth of a forest is burned on purpose in springtime.

The burning of the undergrowth of the forest helps to prevent large, uncontrollable accidental fires that could destroy life and property. By keeping the undergrowth low, any accidental fire or arson will not spread as fast or be as devastating. two research areas in two different locations of the Pine Barrens [1]. One of these locations was in a part of the forest where pines (which have needles) and oaks (which have flat leaves) grow together. We called this the mixed forest. The other location was in a forest with only pine trees, which we called the pines-only forest. Both of these locations had two research sites. One site was burned and the other site was kept from burning. The burning was done on purpose, to control the growth of the bushes growing under the trees, which is also called prescribed burning. The burned sites were burned in Spring of 2011 and 2012. Before the burning treatments, the location with both pines and oaks experienced 2 years when Gypsy moth caterpillars chewed up the leaves of the oaks (in 2007 and 2008) and 2 years of drought (in 2006 and 2010). This allowed us to study how the forest responded to a combination of disturbances. 


\section{HOW WE SET OUT THE EXPERIMENTS}

\section{WHAT HAPPENS WHEN YOU BURN A FOREST}

After we burned the mixed forest and the pines-only forest, we found that when pines grow in a pines-only forest, they are not really affected by fire and, if anything, are better off after the fire. Burned pines took in the same amount of carbon dioxide and released the same amount of water from leaves after the fire as did the unburned pines. Interestingly, the burned pines were more efficient in their photosynthesis, meaning they used fewer nutrients to take up carbon dioxide, compared with the unburned pines. But this effect only lasted about a year. After that, there was no difference between the burned and unburned pines at all. In the mixed forest, the story was a little different. The pines in the mixed forest were negatively affected by the fire, with the result being that the burned pines took up less carbon dioxide after the fire compared with the burned pines in the pinesonly forest. Like the pines-only forest, though, the effect did not last very long-a year after the fire, the burned pines in the mixed forest took up the same amount of carbon dioxide as they did before the fire. In other words, these trees bounce back pretty easily when it comes to fire (see Figure 1 for a summary of these results).

\section{WHAT HAPPENS TO TREES WHEN GYPSY MOTHS CHEW THE LEAVES}

To some level, all trees are adapted to deal with their leaves being chewed up by insects, because it is pretty normal for insects to feed on tree leaves. How the trees respond to leaf chewing depends on the type of tree, the time of year that the chewing happens, and how severely the trees are affected. In 2007, Gypsy moth caterpillars ate all of the leaves of the oak trees in the NJ Pine Barrens. In 2008, some of the leaves, but not all, were eaten. Following the severe loss of leaves, called defoliation, in 2007, the trees regrew their leaves, but only $50 \%$ of the leaf area was replaced (i.e., the trees had $50 \%$ less leaf area compared with the amount they had before the leaves were eaten, meaning that there were fewer leaves on the trees). Leaf area determines the amount of water the trees lose and the amount of carbon dioxide they can take in. In 2007, after the oaks regrew half of their leaves, water loss per tree was

Pine trees mostly showed no effects of prescribed burning after the fires if they grew just by themselves. On the other hand, if they grew mixed in with oaks, they initially had decreased growth, but then the following year their growth was back to normal. The oaks were not checked for their response.

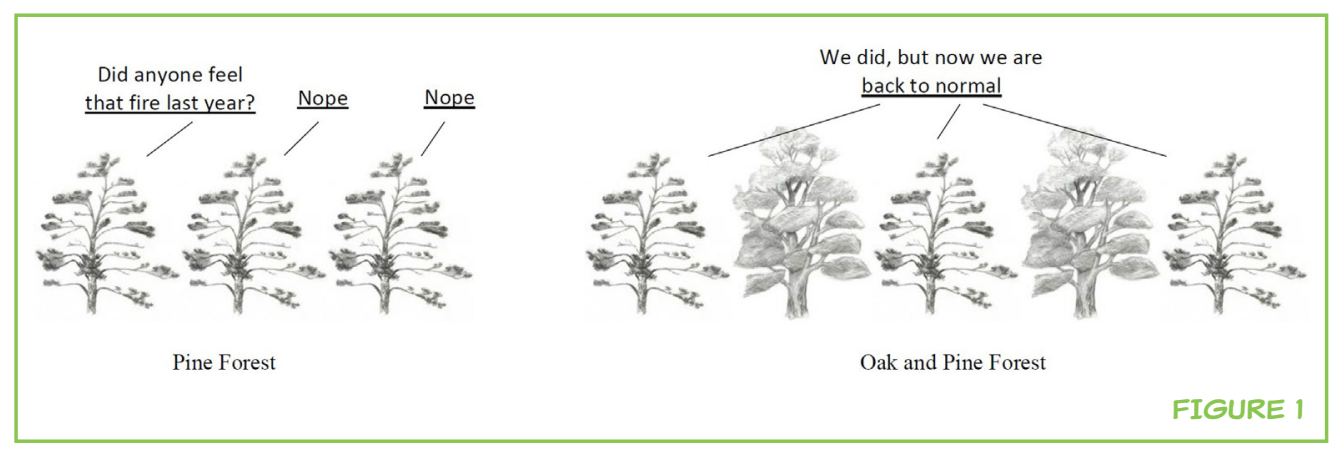


reduced by $25 \%$. However, by 2012,5 years after the severe defoliation, the water loss returned to normal, but the overall ability of the oak trees in the Pine Barrens to take up carbon dioxide was still reduced. This was not because individual trees could not take in carbon dioxide, but because some trees died from the defoliation, so there were fewer trees in the area, overall. So, fewer trees were able to take in carbon dioxide compared with the situation before the Gypsy moth caterpillar attack happened. After the Gypsy moth caterpillar attack and a very severe drought in 2010, one-third of the trees died, mostly oaks (see also below).

The big decrease in carbon dioxide uptake that occurred after fire and the Gypsy moth caterpillar attack was possibly due to the combined effect of the leaves being chewed up in 2007/2008 and then dried up by the drought in 2010, since the drought occurred so soon after the Gypsy moth caterpillar attack. There were some differences in the way different oak species responded to the drought, though. Chestnut oak (Quercus montana) showed a decrease in carbon dioxide uptake compared with black oak (Quercus velutina), but more black oaks died in response to the drought than did chestnut oaks. The pines did not seem to be negatively affected by the caterpillar attack and the drought compared to with the oaks. Our results suggest that if more droughts occur, the kinds of tree species in the Pine Barrens could shift to more pines and maybe more oaks like chestnut oak instead of black oak (see Figures 2 and 3 for a summary of these results).

\section{WHAT DOES IT ALL MEAN?}

Our study showed that when several disturbances happen in a short amount of time, it can be damaging to some trees, but not others. That means that forests made up of different species of trees will respond in different ways to these kinds of disturbances. Our study also showed that trees that are adapted to live with fire can, therefore, quickly recover from fires and quickly return to normal. Understanding how trees respond to different kinds of disturbances is important so that we can predict what might happen to the trees the next time such a disturbance occurs or when these disturbances occur more often, which might happen because of global climate change.

\section{FIGURE 2}

Pine trees mostly did not respond to drought, but oaks did (see also Figure 3). Chestnut oaks had a reduced ability to take up carbon and black oaks died in response to the drought.

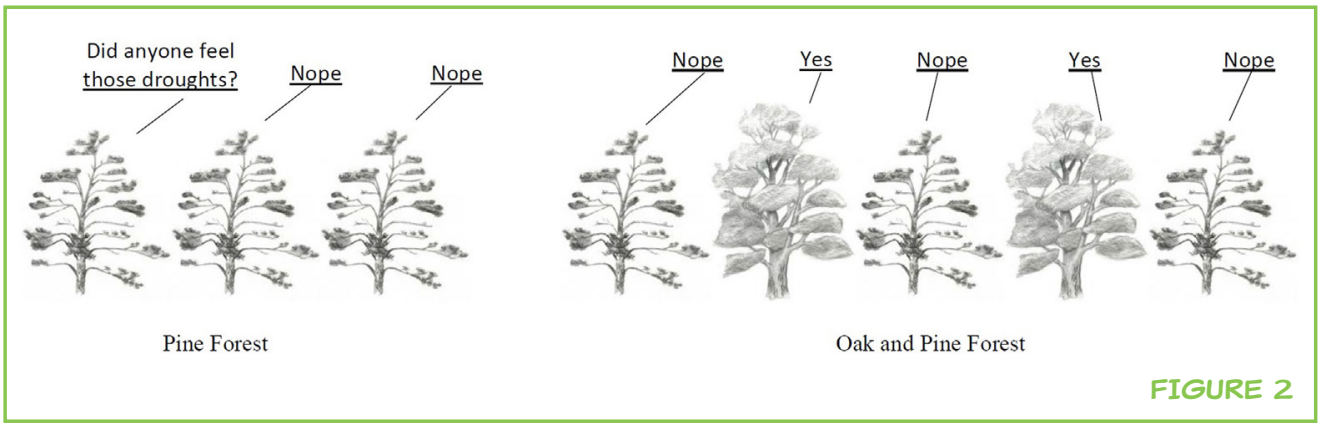




\section{FIGURE 3}

Oak trees had reduced water loss and carbon uptake in 2007 after some of the leaves grew back. In 2012, the oaks had normal water loss, but total carbon uptake was reduced because fewer trees were alive to take in carbon due to a combination of drought and defoliation

(see also Figure 2).

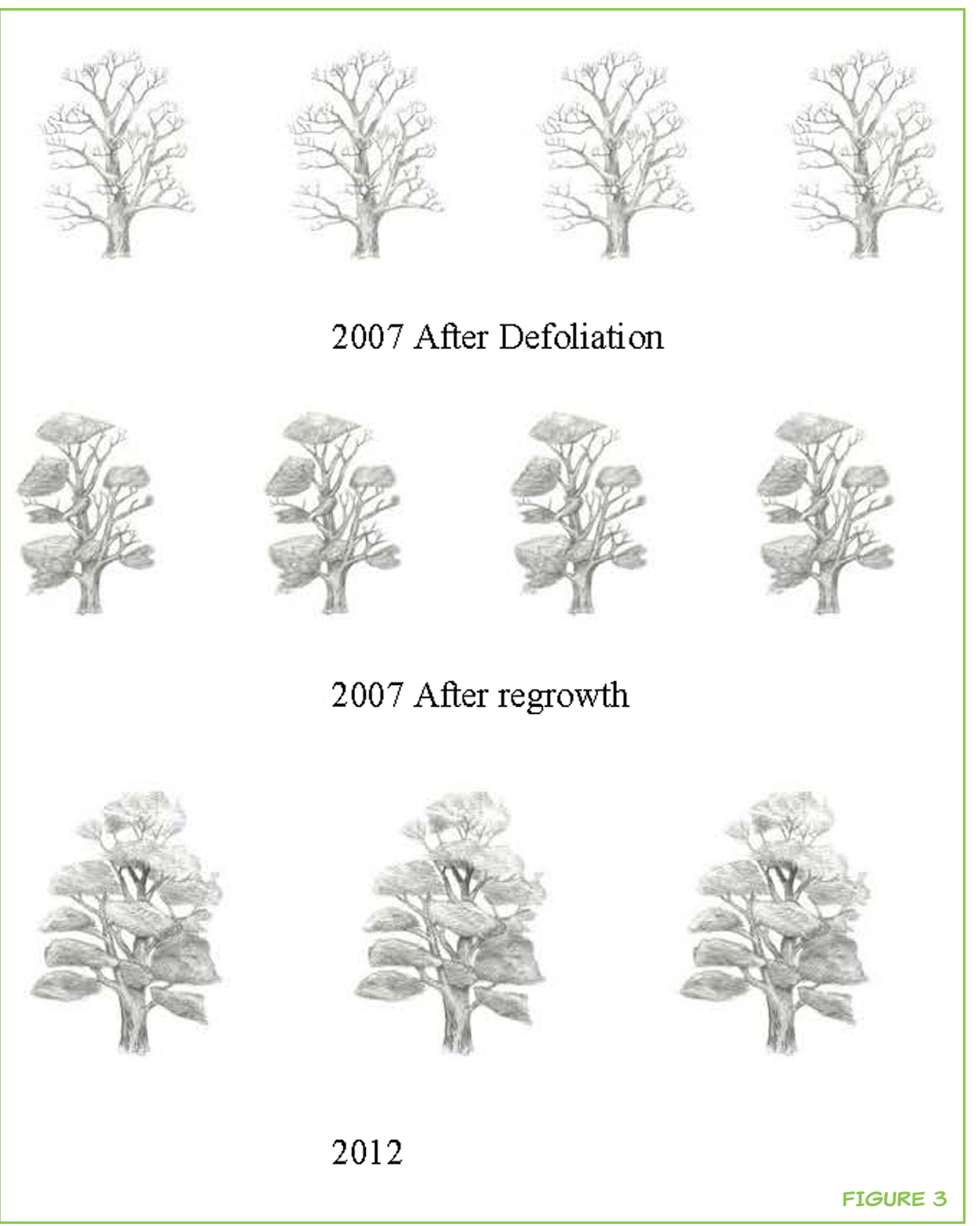

Trees are incredibly important to humans because they provide wood for furniture and construction, the material to make paper, and firewood. Many other species are dependent on trees for food and shelter. Trees also serve as a natural air conditioner for the surrounding areas. Since trees are such an important resource for humans and other species, it is absolutely crucial to study how trees deal with disturbances.

\section{REFERENCE}

1. Schäfer, K. V. R., Renninger, H. J., Carlo, N. J., and Vanderklein, D. 2014. Forest response and recovery following disturbance in upland forests of the Atlantic Coastal Plain. Front. Plant Sci. 5:294. doi:10.3389/fpls.2014.00294 
SUBMITTED: 23 June 2017; ACCEPTED: 15 June 2018;

PUBLISHED ONLINE: 03 July 2018.

EDITED BY: Mark Alan Brandon, The Open University, United Kingdom

CITATION: Schäfer KVR and Vanderklein DW (2018) How Do Trees Respond to Stress? Front. Young Minds 6:33. doi:10.3389/frym.2018.00033

CONFLICT OF INTEREST STATEMENT: The authors declare that the research was conducted in the absence of any commercial or financial relationships that could be construed as a potential conflict of interest.

COPYRIGHT @ 2018 Schäfer and Vanderklein. This is an open-access article distributed under the terms of the Creative Commons Attribution License (CC BY). The use, distribution or reproduction in other forums is permitted, provided the original author(s) and the copyright owner are credited and that the original publication in this journal is cited, in accordance with accepted academic practice. No use, distribution or reproduction is permitted which does not comply with these terms.

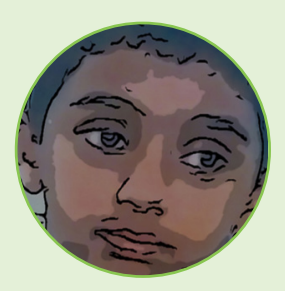

\section{REVIEWED BY}

\section{SASYAK, AGE: 9}

Sasyak is a 9-year-old student from India. He is an avid reader of several genres of books. $\mathrm{He}$ is a keen participant in quiz contests and olympiads, and is a spell bee champion. He attends football classes and enjoys cycling.

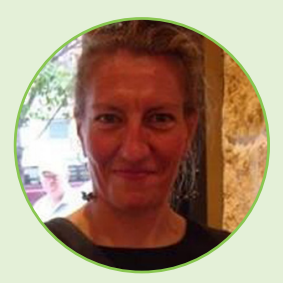

\section{AUTHORS}

\section{KARINA V. R. SCHÄFER}

Karina VR Schäfer is an Ecosystem Ecologist at Rutgers University - Newark, NJ, USA. Her research focuses on greenhouse gas fluxes in terrestrial ecosystems with particular emphasis on global climate change. In this work in particular, the question of how disturbance is changing structure and function of forests and influencing carbon and water cycling on the ecosystem level are investigated. *karinavr@rutgers.edu

\section{DIRK W. VANDERKLEIN}

I am a plant eco-physiologist. That means that I study how plants grow, how the environment they are in affects their growth, and how the plants affect their environment. For example, I am studying how an invasive plant called Japanese knotweed may be impacting the amount of water in the soil and our streams. Other areas of research that I have been involved in are what determines how tall trees grow, what impact soil contamination has on tree growth, and the physiology and ecology of pines and oaks growing in the Pine Barrens of New Jersey and New York. 